diately to the country, where he was directed to use the fluid extract of Bael, with a view to give tone to the stomach and bowels.

On the 26th January, 1852, the Colonel writes:-"Some time ago, owing to imprudent exposure, and very cold feet, my bowels became affected. As they did not of themselves return to their natural state, I had recourse to the Bael. For a day or two I took a dessert-spoonful three times a day. Thinking this too much, I reduced the quantity to twice a day. The taste was rather mawkish at first, but afterwards became agreeable. It has produced the beneficial effect of removing the laxity of the bowels. My appetite is much better than it was before I had this slight return of complaint, and I can venture on both beverage and diet that I dared not touch previously."

This gentleman is now (October, 1852, quite well as to diarrhoea, but is affected with chronic gout in the hands as an hereditary complaint.

Remarks.-Colonel —-'s case affords a good illustration of the fact that chronic diarrhoa of the most formidable character may, and often does, depend on suspended function of the liver. The danger of the case also was extreme; and I believe that, but for the action of mercury, this valuable and accomplished officer must have died;-indeed, he very nearly died on landing in England. This kind of diarrhoa, like some forms of ague, cannot be cured withont mercury, or without nitro-muriatic acid, the action of which is similar. Referring to the gradual subsidence of albumen in the urine, I may here mention that in several instances in which diseased states of the liver or spleen, or of both, existed. I have found albumen in the urine as a functional affection, and it always disappeared on the restoration of health; in other-words, on the removal of the visceral affections.

Astringents, it will be observed, were of no radical avail in this instance, nor was any more here expected from their use than to arrest excessive serous discharges, and thus obtain time for the introduction of the appropriate remedy, which in event proved radical of cure.

(To be continued.)

\section{ELECTRICITY AS A THERAPEUTIC AGENT.}

By CHARLES DIBDIN, Esq., L.S.A.

I TAKE the liberty, generally allowed to a subscriber, of intruding on your columns, I trust for the benefit of medical science. I have ventured on a communication from a distant, although not at present an uninteresting portion of the globe, in consequence of observing the many quackeries at present practised in the old country under various names, and which practice, I conceive, very much tends to divert the genuine practitioner from a legitimate use of the electric fluid.

The following case I hope will prove the efficacy of a proper application of that agent:-

J. S-, a young gentleman of this town, applied to me on Jan. 22, J853, with contraction of the right arm. The history of the case was, that he had fallen from his horse on Dec. 29, 1852, and the animal had trodden on his arm just above the elbow-joint; he paid no attention to it, but kept it up in the flexed position. When $I$ saw it, the ecchymosis, which had been considerable, had subsided, and the arm was firmly fixed in a state of semiflexion. There was a tumour at the origin of the brachialis anticus on the inner side, but the exact parts indicated were not clearly defined, on account of the swelling being considerable; although the tendon of the biceps was contracted, it appeared healthy.

I applied the cantharides plaster over the tumour, and found on the next day that it was softer and more diffused; and on the 25th of January, the swelling having greatly subsided, I defined two patches of what Mr. Fergusson would call solid cedema. One on the inner edge of the brachialis anticus, the other on the inner edge of the biceps, the two so situated that I could grate them one upon the other. Still the arm was in its semiflexed condition, and I determined to have recourse to electricity, which $I$ commenced on the $25 \mathrm{th}$ of January, and continued daily, passing the current chiefly from the origin of the brachialis anticus.

On the 26th I painted the tumours with iodine, and directed the patient to continue its application, which he did rather severely for a few days, but without diminution of the odema. I continued steadily with the electricity, and on the 20 th of February had the satisfaction to discharge my patient with the arm perfectly straightened.

Sloane-street, Goulburn, New South Wales, Feb. 1853.

\section{A Anirror}

OF THE PRACTICE OF

\section{MEDICINE AND SURGERY \\ IN THE}

HOSPITALS OF LONDON.

Nulla est alia pro certo noscendi via, nisi quam plurimas et morborum, et dissectionum historias, tum aliorum proprias, collectas habere et inter se comparare,-Morgagni. De Sed. et Caus, Morb., lib.14. Procemium.

\section{ST. BARTHOLOMEW'S HOSPITAL.}

Valvular Disease of the Heart; Hemiplegia; Gangrene of the Toes.

(Under the care of Dr. Hue.)

Pathologists have of late been finding links between affections which had hitherto been looked upon as quite unconnected, and it may easily be surmised that discoveries in that direction will go on increasing and multiplying the more diseases are watched and studied. For instance, there is a certain chain of affections which are traceable to disease of the arterial system; some are connected, either remotely or intimately, with pathological alterations in the kidney, and others finally depend chiefly on changes gradually going on in the cerebral mass.

We desire to draw attention for a moment to a case now under the charge of Dr. Hue, in which the morbid phenomena, though apparently of a widely different nature, depend, according to all probability, on abnormal action in the coats of certain arteries. In fact, we have in the same subject valvular disease of the heart, hemiplegia, and gangrene of the toes, following each other at short intervals.

The patient is twenty-two years of age, of temperate habits, though he has followed the occupation of potboy in a publichouse, and was admitted March 10,1853 , under the care of Dr. Hue. The man had generally been enjoying pretty good health, and had plenty of strength for his work, though habitually rather pale. About six months before admission he suffered from what he called inflammation of the lungs, was laid up for six weeks, and finally recovered perfectly after staying in the country. Some time before the attack of hemiplegia the patient had had occasional palpitation of the heart, was easily put out of breath in going up stairs, and had occasional headaches. Ten days before admission he suddenly felt giddy whilst engaged in his occupation; he had a moment's unconscionsness, and found that he had lost the use of his left arm and leg. There had not been severe pain in the head previous to this attack, and the general health had been very satisfactory up to the time when the paralysis set in. Medical aid was obtained; but, as after a few days no improvement was noticed, the patient was sent to this hospital.

On admission he was found to have lost the power of voluntary motion in the left arm and leg; speech was, however, unimpaired. There was no severe pain in the head, the pulse was quiet and regular, the skin bedewed with moisture, and the tongue foul. No abnormal signs were noticed in either lung, bnt a very loud systolic bellows sound was heard over the base of the heart.

The patient was put upon a course of mercury, and in a few weeks recovered the use of his leg so far as to be able to walk, but the arm remained powerless, and the bellows sound continued.

It might be inferred from the morbid phenomena presented in this case that the hemiplegia depended on ramollissement of the brain, caused by insufficient supply of blood; the latter circumstance being probably owing to deposits of atheroma or bone in ccrtain portions of the cerebral arteries. But this tendency of morbid action in the conts of the vessels had already been manifested by the valvular derangement at the heart, so that it might be fairly deduced that the hemiplegia arose from the same systemic tendency as the irregular cardiac action. We need hardly say, however, that the cerebral mischief might be explained by an irregular and insufficient supply of blood to the brain, depending on the imperfection of the valves of the heart; but the symptoms which became apparent on the 3rd of June, three months after the patient's admission, seem to warrant the opinion that the coats of the arteries of the brain are in a diseased condition. 